\title{
Pregnancy-Specific Concerns and Psychological Impact of COVID-19 on Antenatal Women
}

\author{
Sanjay SINGH', Vinod NAIR ${ }^{1}$, Virendra Vikram SINGH ${ }^{2}$, Shyamji TIWARI', \\ Devendra ARORA ${ }^{1}$, Madhusudan DEY ${ }^{1}$, Ravindu TIWARI ${ }^{1}$, Sreeni V. NAIR ${ }^{3}$
}

New Delhi, India

\section{ABSTRACT}

OBJECTIVE: The ongoing COVID-19 pandemic is causing widespread concern, fear, stress, anxiety, and depression throughout the population worldwide. Pregnant women, being a vulnerable group, are grossly affected by these changing environmental scenarios. The spread of Corona Virus infection itself and the subsequent nation-wide lockdown in India, just like many other countries, has caused a serious impact on antenatal patients. The objective of this study was to bring out the specific concerns of pregnant women during the ongoing COVID-19 pandemic and also to assess the prevalence of Depression and Anxiety Disorder owing to the pandemic.

STUDY DESIGN: This cross-sectional survey among antenatal patients was conducted in the outpatient department of a tertiary care obstetric center which is also a designated COVID hospital. Prevalidated questionnaires, Personal Health Questionnaire-9 \& Generalized Anxiety Disorder questionnaire-7 were used for data collection. A semi-structured questionnaire was used to evaluate pregnancy-specific concerns of the patients with respect to the COVID-19 pandemic.

RESULTS: The overall prevalence of moderate to severe depression in the survey was found to be $13.2 \%(n=66)$. The prevalence of moderate to severe anxiety disorder was found to be $9.8 \%(n=49)$.

CONCLUSION: This study has brought out the need for urgent attention to the psychological impact of COVID-19 on pregnant women. Pregnant women being a vulnerable group, especially during this pandemic, need special attention to their psychological wellbeing as well.

Keywords: Anxiety, COVID-19 pandemic, Depression, Lockdown, Pregnancy, Stress

Gynecol Obstet Reprod Med 2022;28(2):129-134

\footnotetext{
${ }^{I}$ Department of Obstetrics \& Gynecology, Base Hospital Delhi Cantonment, New Delhi, India

2 Department of Psychiatry, Base Hospital Delhi Cantonment, New Delhi, India

3 Station Health Organization, Ferozepur, Punjab, India

Address of Correspondence: Vinod Nair

Department of Obstetrics \& Gynecology,

Base Hospital Delhi Cantonment,

New Delhi, India, PIN-110010.

nairvinod19@gmail.com
}

Submitted for Publication: 28.11.2020 Revised for Publication: 29.11.2020 Accepted for Publication: 12.03.2021 Online Published: 14.04.2021

ORCID IDs of the authors: SS: 0000-0002-6073-6023

VN: 0000-0001-7715-7346 VVS: 0000-0002-9413-0855

ST: 0000-0001-9007-1651 DA: 0000-0002-8660-6737

MD: 0000-0003-3892-1529 RT: 0000-0003-3963-9074

SVN: 0000-0003-4636-4662

\begin{tabular}{cc}
\hline Quick Response Code: & Access this article online \\
\cline { 2 - 2 } 品 & Website: www.gorm.com.tr \\
e- mail: info@gorm.com.tr \\
\cline { 2 - 2 }
\end{tabular}

How to cite this article: Singh S. Nair V. Singh VV. Tiwari S. Arora D. Dey M. Tiwari R. Nair SV. Pregnancy-specific Concerns and Psychological Impact of COVID-19 on Antenatal Women. Gynecol Obstet Reprod Med. 2022;

28(2): $129-134$

\section{Introduction}

As the Coronavirus Disease-19 (COVID-19) pandemic takes its toll across the world, it is causing widespread concern, fear, stress, anxiety, and depression among all age groups and social strata of people. All these human responses are natural reactions to the changing environment. People of all age groups irrespective of their socio-economic background are affected by this pandemic. However, physical as well as psychological vulnerability varies in different population groups. Women and children are considered the most vulnerable during any pandemic. Care of pregnant women during this scenario of social distancing and national lockdown becomes difficult because of their specific needs which are left unaddressed. Pregnant women, being considered a vulnerable group, are grossly affected by these changing environmental scenarios. The environmental circumstances where a pregnant woman thrives can adversely affect maternal and neonatal health. The occurrence of anxiety or depression in pregnancy not only affects the woman's mental health but also is a risk factor for postnatal disorders and may even have effects on the unborn child. Heron et al. in their study found that $21 \%$ of the antenatal population had clinically significant anxiety symptoms and $64 \%$ of them had continued psychological issues postnatally 
(1). It is a known fact that the environment in which a pregnant woman is exposed can create a permanent imprint on fetal physiology (2). Prenatal maternal stress and anxiety, whether at times of disaster or not, are well-established risk factors for preterm birth, low birth weight, and infant health problems and may have long-lasting effects on the offspring $(3,4)$.

Available data on the psychological impact of COVID-19 on pregnant women are scarce. In two different cross-sectional surveys conducted in China and Italy, it has been found that more than half of the general population had moderate to the severe psychological impact of the outbreak $(5,6)$. Similarly, in India, the spread of Coronavirus infection itself and the subsequent nation-wide lockdown has caused a serious impact on antenatal patients. Their routine antenatal check-ups have been hampered. Many antenatal investigations including ultrasonographic scans have been withheld or delayed. Moreover, most importantly, many pregnant ladies are worried if their unborn babies would be affected if they contract COVID19 infection. Under these circumstances, mental health being an important aspect of any individual, especially a pregnant woman, psychological screening and necessary counseling becomes an apt methodology in the antenatal clinics during the COVID-19 pandemic.

\section{Material and Method}

This cross-sectional survey among antenatal patients was conducted in the outpatient department of a tertiary care obstetric center which is also a designated COVID hospital. The study was approved by the Institute Ethics Committee (Ethics approval reference number: 1156/IEC/07/2020/08 date 31.07.2020) and written informed consent was obtained from every participant. The duration of the study was from 01 June 2020 till 30 September 2020 when the country was in phase1.0 to 4.0 of the unlocking process. Participants of the study included all pregnant women attending the antenatal clinic of the hospital irrespective of their period of gestation and COVID status. The questionnaires were applied face to face by a HealthCare staff. Any patient who had a previous history of Psychiatric illness or peripartum depression was excluded from the survey. Prevalidated questionnaires for psychological impact and a semi-structured questionnaire developed for this study were used for data collection. Personal Health Questionnaire-9 (PHQ-9) \& Generalized Anxiety Disorder questionnaire-7 (GAD-7) are validated screening tools for depression and anxiety disorders developed by Spitzer and colleagues. They are available in the public domain and used worldwide. PHQ-9 is a 9 item, self-administered version of the PRIME-MD (Primary Care Evaluation of Mental Disorders) which has been extensively used for both research and monitoring of depression (7). GAD-7 was originally developed for generalized anxiety disorder and has good sensitivity and specificity for other types of anxiety disorders too (8). The final score was tabulated and analyzed to find out the anxiety level and depression. A cut-off point of 10 or greater on these scales is significant to draw attention to a possible clinically significant condition. Alternatively, the scores have also been classified as mild, moderate, or severe with cut-off points of 5, 10, and 15 respectively. For analysis, a cut-off point of 10 has been used to detect a depressive or anxiety disorder. A semi-structured questionnaire was developed and used to evaluate pregnancy-specific concerns of the patients with respect to the COVID-19 pandemic. This questionnaire was based on the common concerns expressed by the antenatal patients in the outpatient department. All the questionnaires were available in both Hindi and English.

Statistical Analysis: Data analysis was carried out using statistical software (Software STATA version 12.0 by StataCorp, Texas, USA). Descriptive statistics such as mean, standard deviation, and range values were calculated for normally distributed data and a comparison of mean values was done using the student " $\mathrm{t}$ " independent test. Categorical variables were presented as frequency and percentage values. A comparison of categorical variables was carried out using the Chi-square test. For all statistical tests, a two-tailed probability of $<0.05$ was considered statistically significant.

\section{Results}

A total of 500 patients were enrolled in the survey as per inclusion criteria. Socio-demographic characteristics of the study participants are as depicted in table I. The mean age of the participants of the survey was found to be 27 years with the minimum age being 18 years and a maximum of 41 years. The socioeconomic status of the participants was assessed as per the modified Kuppuswamy scale. Nearly 7.0\% $(n=35)$ participants were in the upper socioeconomic class, $62.2 \%$ $(\mathrm{n}=311)$ in the upper middle, $20.4 \%(\mathrm{n}=102), 7.4 \%(\mathrm{n}=37)$ in the upper-lower and $3.0 \%(n=15)$ in the lower socioeconomic

Table I: Socio-demographic characteristics of study participants

\begin{tabular}{lll}
\hline Characteristic & & Frequency \\
\hline \multirow{3}{*}{ Age (years) } & $18-25$ & $38.8 \%(n=194)$ \\
& $26-35$ & $57.2 \%(n=286)$ \\
& $36-45$ & $5 \%(n=20)$ \\
& Upper & $7.0 \%(n=35)$ \\
Socio-Economic & Upper Middle & $62.2 \%(n=311)$ \\
Background & Lower Middle & $20.4 \%(n=102)$ \\
& Upper Lower & $7.4 \%(n=37)$ \\
& Lower & $3.0 \%(n=15)$ \\
Parity & Primigravidae & $51.6 \%(n=258)$ \\
& Multigravidae & $48.4 \%(n=242)$ \\
Period of Gestation & 1 $^{\text {st }}$ Trimester & $32 \%(n=160)$ \\
& $3^{\text {rd }}$ Trimester & $46 \%(n=230)$ \\
& & $22 \%(n=110)$ \\
\hline
\end{tabular}


class. $51.6 \%(\mathrm{n}=258)$ cases in the study were primigravidae and the remaining $48.4 \%(n=242)$ were multigravidae. The majority of the patients were in their second trimester; $46 \%(\mathrm{n}=230)$ with the remaining $32 \%(\mathrm{n}=160)$ in the first trimester and $22 \%(n=110)$ in the third trimester of pregnancy. None of the participants gave a history of any previous psychiatric illness or peripartum depression.

The prevalence of depression in the survey was found to be $13.2 \%(n=66)$. The prevalence in the age group 18-25 years was found to be the highest; $23.71 \%(\mathrm{n}=46)$ and the lowest in the 2635 years age group; $5.95 \%(\mathrm{n}=17)$, which is statistically significant, $p<0.0001$. Prevalence among primigravidae was found to be more; $16.67 \%$ $(\mathrm{n}=43)$ as compared with multigravidae; $9.5 \%$ $(\mathrm{n}=23), p=0.0256$. The maximum prevalence of depression was found in the first trimester, $28.75 \%(\mathrm{n}=46)$ and the least in the third trimester, $4.55 \%(\mathrm{n}=5) ; p<0.0001$ as depicted in table II.

The prevalence of anxiety disorder was found to be $9.8 \%(\mathrm{n}=49)$. The maximum prevalence was in the age group $36-45$ years, $80 \%(\mathrm{n}=16)$ and the least in the age group $26-35$ years, $3.5 \%(\mathrm{n}=10)$ which is statistically significant; $p<0.0001$ as depicted in table II. The prevalence was more in multigravidae, $13.22 \%(\mathrm{n}=32)$ as compared with primigravidae, $6.59 \%(\mathrm{n}=17) ; p=0.0191$. The maximum prevalence of anxiety disorder was found in the third trimester, $40 \%(\mathrm{n}=44)$, and the least in the first trimester, $1.25 \%(\mathrm{n}=2) ; p<0.0001$.

Table III depicts the responses of the participants to the questionnaire on pregnancy-specific concerns during the COVID-19 pandemic. At least $30-35 \%$ of the participants believed that Coronavirus infection is harmful to their pregnancy (response to question nos. 1, 7, and 8). Around $30.6 \%(\mathrm{n}=153)$ of the participants believed that pregnant women are more susceptible to COVID-19 infection and $40.6 \%(n=218)$ believed that if a pregnant lady contracted COVID19 , her condition can worsen as compared with the non-pregnant individual. Nearly $12-18 \%$ of the study participants have had a reduced number of antenatal visits due to fear of contracting COVID-19. Only $10.8 \%$ would opt for Caesarean Delivery due to fear of contracting the disease. Many of them (33\%) expected prolonged hospitalization if they were tested positive for COVID19. Contraceptive measures were considered more important during the COVID-19 pandemic by $27.8 \%(n=139)$ of the study participants.

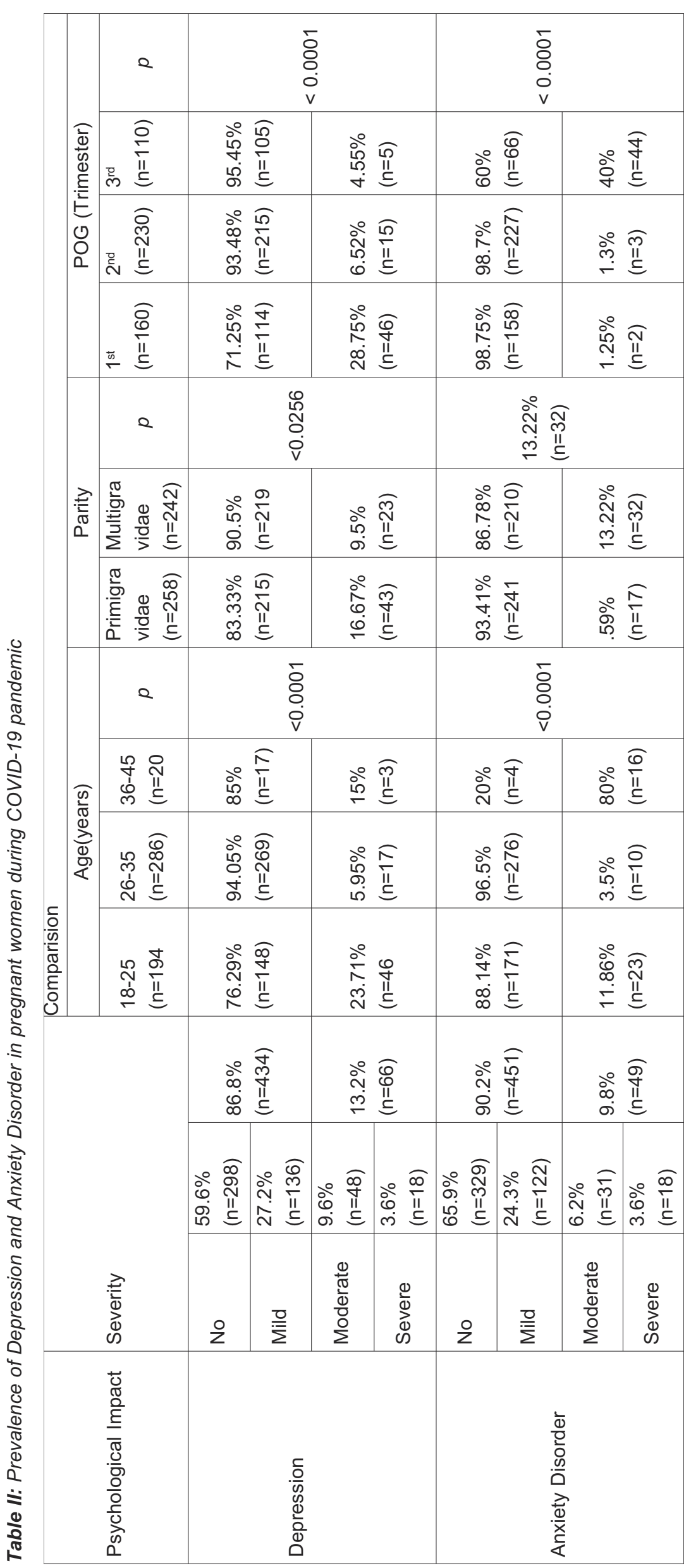


Table III: Response of patients to Questionnaire on Obstetric well-being during Covid-19 pandemic.

\begin{tabular}{|c|c|c|c|c|c|}
\hline \multirow[t]{2}{*}{ S No } & \multirow[t]{2}{*}{ Questions } & \multicolumn{2}{|c|}{ Response } & \multirow[t]{2}{*}{$p$} & \multirow[t]{2}{*}{$95 \%$ C.I } \\
\hline & & Yes & No & & \\
\hline 1 & $\begin{array}{l}\text { Do you think/believe that COVID-19 is harmful to your preg- } \\
\text { nancy? }\end{array}$ & $\begin{array}{l}35 \% \\
(n=175)\end{array}$ & $65 \%(n=325)$ & $<0.0001$ & $58.89 \%$ to $68.41 \%$ \\
\hline 2 & $\begin{array}{l}\text { Do you think/believe that visiting an antenatal clinic or } \\
\text { Ultrasound clinic makes you more susceptible to Coronavirus in- } \\
\text { fection? }\end{array}$ & $\begin{array}{l}18 \% \\
(n=90)\end{array}$ & $82 \%(n=410)$ & $<0.0001$ & $23.94 \%$ to $35.73 \%$ \\
\hline 3 & $\begin{array}{l}\text { Do you think/believe that your antenatal check-up frequency has } \\
\text { reduced in the last } 3 \text { months? }\end{array}$ & $\begin{array}{l}12.8 \% \\
(n=64)\end{array}$ & $87.2 \%(n=436)$ & $<0.0001$ & $69.85 \%$ to $78.14 \%$ \\
\hline 4 & $\begin{array}{l}\text { Do you think/believe that you may have to undergo a Caesarean } \\
\text { delivery only because of the COVID-19 situation? }\end{array}$ & $\begin{array}{l}10.8 \% \\
(n=54)\end{array}$ & $89.2 \%(n=451)$ & $<0.0001$ & $74.12 \%$ to $81.83 \%$ \\
\hline 5 & $\begin{array}{l}\text { Do you think/believe that pregnant women are more susceptible } \\
\text { to Coronavirus infection? }\end{array}$ & $\begin{array}{l}30.6 \% \\
(n=153)\end{array}$ & $69.4 \%(n=347)$ & $<0.0001$ & $32.89 \%$ to $44.28 \%$ \\
\hline 6 & $\begin{array}{l}\text { Do you think/believe that if a pregnant woman contracts COVID- } \\
19, \text { her condition can be worse than other non-pregnant ladies? }\end{array}$ & $\begin{array}{l}43.6 \% \\
(n=218)\end{array}$ & $56.4 \%(n=282)$ & $=0.0001$ & $6.60 \%$ to $18.85 \%$ \\
\hline 7 & $\begin{array}{l}\text { Do you think/believe that if you get COVID-19, your baby inside } \\
\text { your womb also can get infected? }\end{array}$ & $\begin{array}{l}31.2 \% \\
(n=156)\end{array}$ & $68.8 \%(n=344)$ & $<0.0001$ & $31.67 \%$ to $43.12 \%$ \\
\hline 8 & $\begin{array}{l}\text { Do you think/believe that if your baby contracts COVID-19 while } \\
\text { in your womb, it can have a gross harmful effect on your baby? }\end{array}$ & $\begin{array}{l}35.4 \% \\
(n=177)\end{array}$ & $64.6 \%(n=323)$ & $<0.0001$ & $23.13 \%$ to $34.94 \%$ \\
\hline 9 & $\begin{array}{l}\text { Do you think/believe that Coronavirus can be transmitted by } \\
\text { breastfeeding? }\end{array}$ & $\begin{array}{l}23 \% \\
(n=115)\end{array}$ & $77 \%(n=385)$ & $<0.0001$ & $48.50 \%$ to $58.91 \%$ \\
\hline 10 & $\begin{array}{l}\text { Do you think/believe that you won't get adequate care for your } \\
\text { pregnancy/delivery if you test positive for COVID-19 while get- } \\
\text { ting admitted? }\end{array}$ & $\begin{array}{l}16.6 \% \\
(n=83)\end{array}$ & $83.4 \%(n=417)$ & $<0.0001$ & $61.83 \%$ to $71.04 \%$ \\
\hline 11 & $\begin{array}{l}\text { Do you think/believe that you should stay in hospital till your } \\
\text { COVID test becomes negative? }\end{array}$ & $\begin{array}{l}33 \% \\
(n=165)\end{array}$ & $67 \%(n=335)$ & $<0.0001$ & $28.00 \%$ to $39.62 \%$ \\
\hline 12 & $\begin{array}{l}\text { Do you think or believe that the use of contraceptive measures } \\
\text { is even more important during the Corona period? }\end{array}$ & $\begin{array}{l}27.8 \% \\
(n=139)\end{array}$ & $72.2 \%(n=361)$ & $<0.0001$ & $38.62 \%$ to $49.69 \%$ \\
\hline
\end{tabular}

\section{Discussion}

Pregnancy is a very sensitive time during any woman's life. Along with many physiological changes, a pregnant woman may have various psychological changes occurring during this period. Historically, pregnant women have been placed at risk during pandemics. For example, pregnancy was associated with high mortality rates during the H1N1 "swine flu" pandemic and the severe acute respiratory syndrome (SARS) pandemic $(9,10)$. It is quite common for a pregnant lady to be concerned about various aspects of her pregnancy and her unborn baby. This gets paramount importance during this era of the COVID-19 pandemic. Nationwide lockdown and other restrictions have caused widespread concern among the population irrespective of their age, sex, and socioeconomic status. In an online survey conducted recently in India, it was suggested that more than two-fifths of the people were experiencing common mental disorders, due to lockdown and the prevailing COVID-19 pandemic (11). This finding also suggested that there was a need for expanding mental health services to everyone in the society during this pandemic situ- ation. Another study by Ayaz et.al, from Türkiye, indicated that the COVID-19 outbreak affects the mental health of pregnant women negatively which leads to adverse birth outcomes (12). A similar survey conducted among pregnant Turkish women suggested that the coronavirus pandemic had significant potential for the creation of anxiety, adversity, and fear, creating a negative emotional effect (13). Nanjundaswamy et.al., in their survey conducted amongst Obstetricians across India, have found that the nationwide lockdown has created difficulties for pregnant women to travel to hospitals and to get their scans done on time and caused concerns related to acquiring the infection at hospitals (14). Royal College of Obstetricians and Gynaecologists (RCOG) recommends that every pregnant woman be asked about her psychological wellbeing during antenatal visits especially during the COVID-19 pandemic (15). In our study, we have tried to bring out the common concerns as expressed by the pregnant women attending the antenatal clinic. It has been found that a major proportion of the pregnant population is concerned about their pregnancy owing to the existing COVID-19 pandemic. This 
also depicts the general awareness about the COVID-19 pandemic and its impact on pregnant ladies.

In a recent study conducted in Canada, researchers found that clinically significant levels of anxiety and depression were higher in the COVID-era pregnancy group as compared with the pre-COVID-era group; $10.9 \%$ vs. $6.0 \%$ (16). In our survey, the overall prevalence of depression and anxiety disorder was found to be $13.2 \%$ and $9.8 \%$ respectively. Saccone et al. in their study found that women in the first trimester of pregnancy during the COVID-19 pandemic had higher anxiety and more severe psychological impact as compared with those in the second and third trimester (6). In our study, depression was found to be more common in the first trimester of pregnancy as compared with the second and third trimester, whereas, anxiety disorder was more common in the third trimester. Furthermore, in our study, it was found that young primigravidae were more susceptible to depression. On the other hand, elderly multigravidae had more anxiety symptoms comparatively. Yan et al, in a systematic analysis of 23 studies found that prevalence rates of anxiety, depression, psychological distress, and insomnia among pregnant women during the COVID-19 pandemic were more as compared with the pre-COVID era. In the same analysis, it was also found that multigravidae and women in the first and third trimesters of pregnancy were more vulnerable as compared with other pregnant women (17). In a survey conducted in Sri-Lanka, it was found that multigravidae were more susceptible to anxiety and depression as compared with primigravidae. Also, in the same study, it was found that younger women had a more psychological impact as compared with older ones (18). These statistical differences can be easily explained by the different emotional conditions during pregnancy with respect to the general population as well as their socioeconomic and ethnic background.

\section{Conclusion}

The psychological burden of the COVID-19 pandemic is much more than anticipated. Our study has brought out the need for urgent attention to the psychological impact of COVID-19 on pregnant women. Pregnant women being a vulnerable group, especially during this pandemic, need special attention to their psychological wellbeing. Policymakers should address the specific concerns voiced by the pregnant ladies as a separate entity. Another important aspect is the need of training the Obstetric care providers in the diagnosis and management of psychological issues of pregnant women. It is suggested that every antenatal outpatient clinic should incorporate a counseling cell and helpline number to identify and manage the psychological issues of pregnant women during this pandemic. Our study has the limitation of a small sample size and non-elimination of other co-existing medical disorders. We recommend larger cohort studies as well as "door-knock" surveys on this subject to gather more information and formulate more concrete evidence.
Acknowledgment: We are grateful to all participants and their families who spent their precious time and participated in this research program. We are also thankful for the tireless efforts of the research team members.

Conflict of Interest: The authors declare that they have no competing interests.

Funding: This study was not supported by any financial grant from any agency.

Ethics approval and consent to participate: All participants signed informed written consent before being enrolled in the study. The study was reviewed and approved by the Institutional Ethics Committee of Base Hospital \& Army College of Medical Sciences Delhi Cantonment (Ethics approval reference number: 1156/IEC/07/2020/08 date 31.07. 2020). All procedures were performed according to the Declaration of Helsinki.

Availability of data and materials: The data supporting this study is available through the corresponding author upon reasonable request.

Authors' contributions: Sanjay Singh and Vinod Nair raised the presented idea. Virendra Vikram Singh, Shyamji Tiwari, and Devendra Arora designed the study. Sreeni V Nair conducted the analyses. Madhusudan Dey and Ravindu Tiwari developed the first draft of the manuscript. All authors contributed to the writing of the paper, and have read and approved the final manuscript.

\section{References}

1. Heron J, O'Connor TG, Evans J, Golding J, Glover V; ALSPAC Study Team. The course of anxiety and depression through pregnancy and the postpartum in a community sample. J Affect Disord. 2004;80(1):65-73. Doi: 10. 1016/j. jad. 2003;08.004.

2. Barker DJ. The developmental origins of adult disease. Eur J Epidemiol. 2003;18(8):733-6. Doi: 10.1023/a:102 5388901248.

3. Harville E, Xiong X, Buekens P. Disasters and perinatal health: a systematic review. Obstet Gynecol Surv. 2010; 65(11):713-28. Doi: 10.1097/OGX.0b013e31820 eddbe.

4. Ibrahim SM, Lobel M. Conceptualization, measurement, and effects of pregnancy-specific stress: review of research using the original and revised Prenatal Distress Questionnaire. J Behav Med. 2020;43(1):16-33. Doi: 10. 1007/s10865-019-00068-7.

5. Wang C, Pan R, Wan X, Tan Y, Xu L, Ho CS, Ho RC. Immediate Psychological Responses and Associated Factors during the Initial Stage of the 2019 Coronavirus Disease (COVID-19) Epidemic among the General Population in China. Int J Environ Res Public Health. 2020;17(5):1729. Doi: 10.3390/ijerph17051729.

6. Saccone G, Florio A, Aiello F, Venturella R, De Angelis MC, Locci M, Bifulco G, Zullo F, Di Spiezio Sardo A. Psychological impact of coronavirus disease 2019 in pregnant women. Am J Obstet Gynecol. 2020;223(2):293-295. 
Doi: 10.1016/j.ajog.2020.05.003.

7. Spitzer RL, Williams JB, Kroenke K, Hornyak R, McMurray J. Validity and utility of the PRIME-MD patient health questionnaire in assessment of 3000 obstetricgynecologic patients: the PRIME-MD Patient Health Questionnaire Obstetrics-Gynecology Study. Am J Obstet Gynecol. 2000;183(3):759-69. Doi: 10.1067/mob.2000. 106580 .

8. Spitzer RL, Kroenke K, Williams JB, Löwe B. A brief measure for assessing generalized anxiety disorder: the GAD-7. Arch Intern Med. 2006;166(10):1092-7. Doi: 10. 1001/archinte.166.10.1092.

9. Mosby LG, Rasmussen SA, Jamieson DJ. 2009 pandemic influenza $\mathrm{A}(\mathrm{H} 1 \mathrm{~N} 1)$ in pregnancy: a systematic review of the literature. Am J Obstet Gynecol. 2011;205(1):10-8. Doi: 10.1016/j.ajog.2010.12.033.

10. Lam CM, Wong SF, Leung TN, Chow KM, Yu WC, Wong TY, et al. A case-controlled study comparing clinical course and outcomes of pregnant and non-pregnant women with severe acute respiratory syndrome. BJOG. 2004;111(8):771-4. Doi: 10.1111/j.1471-0528.2004.001 99.x.

11. Grover S, Sahoo S, Mehra A, Avasthi A, Tripathi A, Subramanyan A, et.al. Psychological impact of COVID19 lockdown: An online survey from India. Indian J Psychiatry. 2020;62(4):354-62. Doi: 10.4103/psychiatry. IndianJPsychiatry_427_20.

12. Ayaz R, Hocaoğlu M, Günay T, Yardımcı OD, Turgut A, Karateke A. Anxiety and depression symptoms in the same pregnant women before and during the COVID-19 pandemic. J Perinat Med. 2020;48(9):965-70. Doi:10. 1515/jpm-2020-0380.

13. Mizrak Sahin B, Kabakci EN. The experiences of pregnant women during the COVID-19 pandemic in Türkiye: A qualitative study. Women Birth. 2021;34(2):162-169. Doi: 10.1016/j.wombi.2020.09.022.

14. Nanjundaswamy MH, Shiva L, Desai G, Ganjekar S, Kishore T, Ram U, et al. COVID-19-related anxiety and concerns expressed by pregnant and postpartum women-a survey among obstetricians. Arch Womens Ment Health. 2020;23(6):787-90. Doi: 10.1007/s00737-020-01060-w.

15. Royal College of Obstetrics and Gynaecologists, RCOG, 2020. Coronavirus infection and pregnancy. Available at: https://www.rcog.org.uk/en/guidelines-research-services/guidelines/coronavirus-pregnancy/covid-19-virusinfection-and-pregnancy/\#advice.

16. Berthelot, N, Lemieux, R, Garon-Bissonnette, J, DrouinMaziade, C, Martel, É, Maziade, M. Uptrend in distress and psychiatric symptomatology in pregnant women during the coronavirus disease 2019 pandemic. Acta Obstet Gynecol Scand. 2020;99(7):848-55. Doi: 10.1111/aogs. 13925.

17. Yan H, Ding Y, Guo W. Mental health of pregnant and postpartum women during the Coronavirus Disease 2019 pandemic: A systematic review and meta-analysis. Front Psychol. 2020;11:617001. Doi: 10.3389/fpsyg. 2020. 617001

18. Patabendige M, Gamage MM, Weerasinghe M, Jayawardane A. Psychological impact of the COVID-19 pandemic among pregnant women in Sri Lanka. Int J Gynaecol Obstet. 2020;151(1):150-3. Doi:10.1002/ijgo. 13335. 